\title{
THE USES OF TRICHLORETHYLENE IN ANALYTICAL CHEMISTRY.*
}

\author{
By L. GOWING-SCOPES.
}

(Read at the Meeting, May 4, 1910.)

THE manufacture of the chlorine derivatives of ethane and ethylene is now carried out on a commercial scale in England, and a series of these products has lately been placed on the market at prices which compare favourably with those of benzene, ether, etc.

The makers give the following list of new products :

\begin{tabular}{lllllr} 
& \multicolumn{3}{c}{ Sp. Gr. } & & B.-Pt. \\
Tetrachlorethane $\left(\mathrm{C}_{2} \mathrm{H}_{2} \mathrm{Cl}_{4}\right)$ & $\ldots$ & $\ldots$ & 1.6 & $\ldots$ & $147^{\circ} \mathrm{C}$. \\
Pentachlorethane $\left(\mathrm{C}_{2} \mathrm{HCl}_{5}\right)$ & $\ldots$ & $\ldots$ & 1.7 & $\ldots$ & $159^{\circ} \mathrm{C}$. \\
Dichlorethylene $\left(\mathrm{C}_{2} \mathrm{H}_{2} \mathrm{Cl}_{2}\right)$ & $\ldots$ & $\ldots$ & 1.25 & $\ldots$ & $55^{\circ} \mathrm{C}$. \\
Trichlorethylene $\left(\mathrm{C}_{2} \mathrm{HCl}_{3}\right)$ & $\ldots$ & $\ldots$ & $1 \cdot 47$ & $\ldots$ & $88^{\circ} \mathrm{C}$. \\
Perchlorethylene $\left(\mathrm{C}_{2} \mathrm{Cl}_{4}\right)$ & $\ldots$ & $\ldots$ & 1.62 & $\ldots$ & $121^{\circ} \mathrm{C}$.
\end{tabular}

These compounds are described as clear liquids of a detergent nature, immiscible with water, non-inflammable, and non-explosive; only two, however-dichlorethylene and trichlorethylene-have boiling-points below that of water. For this reason we are confined to these two as laboratory reagents. Dichlorethylene is the more expensive, and cannot readily be obtained quite pure in quantities; and it, therefore, appeared that trichlorethylene (commercially known as "Westrosol") would be the solvent of most practical interest in analytical chemistry, and a detailed examination of its properties was accordingly undertaken.

Physical Properties.-Trichlorethylene is a colourless mobile liquid, with a

* This work was carried out in accordance with the terms of the Analytical Investigation Scheme. 
pleasant ethereal odour resembling that of chloroform. The following physical constants were determined on a purified sample:

Specific Gravity.-

$\begin{array}{ccccc}\text { Temperature. } & & \text { Sl. Gr. } & & \text { Vt. } \\ 0^{\circ} \mathrm{C} . & \ldots & 1 \cdot 4996 & \ldots & \overline{V_{0} .} \\ 15^{\circ} \mathrm{C} . & \ldots & 1.4762 & \ldots & 1 \cdot 0158 \\ 30^{\circ} \mathrm{C} . & \ldots & 1.4514 & \ldots & 1.0331 \\ 45^{\circ} \mathrm{C} . & \ldots & 1.4262 & \ldots & 1.0515 \\ 59.5^{\circ} \mathrm{C} . & \ldots & 1.3997 & \ldots & 1.0714\end{array}$

It will be seen from the above table that trichlorethylene expands rapidly, and as it also evaporates quickly, the fourth place of decimals could only be obtained approximately. The figures obtained, therefore, did not justify the calculation of a formula for the coefficient of expansion. Trichlorethylene boils at $87.5^{\circ} \mathrm{C}$., and has a refractive index with sodium light at $19 \cdot 8^{\circ} \mathrm{C} .[\mathrm{N}]_{\mathrm{D}}=1 \cdot 4777$.

The specific heat was determined in a calorimeter with a coil of iron wire heated by an electric current at constant voltage. Thermometer readings were taken every half-minute, and heating and cooling curves obtained between the temperatures $20^{\circ} \mathrm{C}$. and $30^{\circ} \mathrm{C}$. From these curves and similar curves prepared for water, the figure $0 \cdot 256$ was calculated.

Trichlorethylene distils approximately thirteen times as fast as water in a current of steam. It is non-inflammable.

Purification.-The liquid was shaken up with a strong neutral solution of silver nitrate to remove chlorine and hydrochloric acid, and was carefully separated. It was then allowed to stand over small lumps of fairly pure quicklime for several hours to remove the bulk of the water, and fractionated, care being taken to reject all that distilled above $90^{\circ} \mathrm{C}$., as commercial trichlorethylene contains a solid compound which seems to be volatile just above this temperature. The distillate was allowed to run on to some freshly fused calcium chloride mixed with a little potassium carbonate; and, when the distillation was complete, the liquid was well shaken up with this mixture, filtered, and distilled from phosphorus pentoxide.

The distillate should be kept in the dark over recently ignited potassium carbonate, and filtered before using. If a specially pure product be required, it may be shaken up with strong sulphuric acid, allowed to separate, the trichlorethylene run off and distilled over roughly powdered caustic soda. As soluble matter is readily extracted from cork by this liquid, it is essential that all joints in the distillation apparatus should be ground together; or, if corks must be used, they should be carefully covered inside and out with a double layer of tinfoil.*

Solvent Properties-Inorganic Compounds.-Of inorganic substances the following were found to be soluble: The three mercuric halides, nitrous acid, ammonia, hydrogen sulphide, chlorine, bromine, iodine, and sulphur.

Sodium and potassium attack trichlorethylene slowly.

* Since writing this plaper it has been found that a purer quality of trichlorethylene than that used in the investigation may be obtained, and would probably only require a simple purification. 
Organic Compounds-Hydrocarbons (eleven examined).-All were soluble, whether aliphatic or aromatic.

Haloid derivatives of hydrocarbons (eight examined) were all soluble.

Acids. - Fatty acids (ten examined) were soluble, as also were sebacic, benzoic, salicylic, mandelic, and cinnamic acids. Lactic acid was sparingly soluble, and oxalic, malonic, succinic, malic, tartaric, citric, mucic, gallic, tannic, and meconic acids were insoluble.

Alcohols (twelve examined).-All were soluble, with the exception of glycerol, which is very slightly soluble, and mannitol, which is insoluble.

Phenols.-The monohydric phenols, including $p$-methylaminophenol (metol), were soluble, whilst the dihydric phenols were insoluble.

Ethers.-Ethyl, $\beta$-naphthylmethyl, guaiacol, and eugenol were all soluble.

Aldehydes.-Formaldehyde, acetaldehyde, paraldehyde, chloral hydrate $o, m$, and $p$, benzaldehyde, cinnamic aldehyde, salicylaldehyde, anisaldehyde, vanillin, furfuraldehyde, butyl, chloral $p$-dimethylaminobenzaldehyde; ketones, acetone and camphor, also alizarine (sparingly), were soluble; trioxymethylene was, however, insoluble.

All esters, including glycerides, were found to be soluble. Carbohydrates glucosides, and proteins were insoluble. The whole of the sixteen bases examined were soluble, but their salts were insoluble.

Nitro compounds (eight examined) were all soluble.

Acetamide, oxamide, benzamide, asparagine, glycine, phenacetin, caffeine, and theobromine were soluble; but uric and hippuric acids, thiourea, urea, creatine, and ammonium urate did not dissolve.

Acetanilide and its $p$-brom-derivative, sulphonal, and saccharin were soluble.

Of dyes, indigo carmine, methyl blue, and nigrosin blue were insoluble, while chrysoidine, Nicholson's blue, malachite green, aniline and methyl oranges, aniline purple and rosaniline were soluble.

Gum arabic, tragacanth, kino, black catechu, eucalyptus, and jalap were insoluble; while ammoniacum, myrrh, copal, asafœetida, benzoin (Siam and Sumatra), gamboge, frankincense, indiarubber and chlorophyll dissolved.

Trichlorethylene was tried as a menstruum for extracting alkaloids; narcotine was extracted both from an acid and alkaline solution, and morphine was not extracted from either. The other alkaloids-atropine, cocaine, quinine, cinchonine, strychnine, brucine, veratine, pilocarpine, and aconitine-were extracted from an alkaline, but not from an acid solution.

It is interesting to note that acids containing two or more carboxyl groups are insoluble in trichlorethylene, whilst monocarboxylic acids are soluble. The presence of one hydroxyl group in an acid renders it difficultly soluble, and two or more make it practically insoluble. Of the acids examined, six containing two or more carboxyl groups were insoluble-viz., oxalic, malonic, succinic, malic, tartaric, and citric; two containing one hydroxyl and carboxyl groups-lactic and salicylic-were sparingly soluble; while gallic and tannic acids containing two or more hydroxyl groups were insoluble. Phthalic acid is an apparent exception to the first case; 
however, it is only soluble to the extent of about 0.2 grm. per 100 c.c. of solution, and this may be due to the presence of anhydride.

Among other compounds the presence of two or more hydroxyl groups renders the compound sparingly soluble or insoluble in a like manner. Of the compounds investigated, in the alcohol group there is glycerol, containing 3, and mannitol, $6-\mathrm{OH}$ groups, and both are insoluble. In the phenol group, catechol, resorcinol, quinol, pyrogallol, and phloroglucinol are insoluble. Saligenin, which is both alcohol and phenol, is sparingly soluble. The carbohydrates (hydroxyaldehydes and hydroxyketones) are all insoluble. Glucosazone is sparingly soluble. The insolubility of the glucosides (amygdalin and salicyn) is interesting, as is also the sparing solubility of alizarine and phenolphthalein, both of which contain two - $\mathrm{OH}$ groups.

Among the inorganic compounds the most interesting is the solubility of nitrous acid. Trichlorethylene readily dissolves this compound, forming a green liquid, which appears to keep fairly well for some time. It should prove useful for diazotisation when the presence of water is objectionable.

Water is only slightly soluble in trichlorethylene. Attempts to determine the amount, owing to the fact that all the substances available would only extract a part of it, were unsuccessful.

Trichlorethylene can be used for the estimation of fats. After numerous experiments it was found to possess distinct advantages over ether, petroleum ether, and other solvents for this purpose. The chief advantages it presents are its noninflammability, and that the fat-flask may be heated directly with a flame, thus doing away with the usual water-bath. The high boiling-point $\left(87.5^{\circ} \mathrm{C}\right.$.), however, is somewhat of a disadvantage.

Estimations of fat were made with this solvent and were compared with the results obtained by ether extraction.

The following are some examples:

\begin{tabular}{ll|c|c|c}
\hline \multicolumn{1}{c|}{ Substance. } & & $\begin{array}{c}\text { Fat, Per Cent., by } \\
\text { extraction with } \\
\text { Trichlorethylene. }\end{array}$ & $\begin{array}{c}\text { Fat, Per Cent., by } \\
\text { extraction with Ether } \\
\text { deternined by Dyer. }\end{array}$ & Difference, Per Cent. \\
\hline Soya beans ... & $\ldots$ & 18.45 & 18.48 & -0.03 \\
Ground-nut cake & $\ldots$ & $7 \cdot 45$ & $7 \cdot 47$ & -0.02 \\
Rice meal ... & $\ldots$ & 4.05 & 4.00 & +0.05 \\
Cotton cake ... & $\ldots$ & 5.45 & 5.43 & +0.02 \\
Sesame cake & $\ldots$ & 15.70 & 15.70 & \pm 0.00 \\
\hline
\end{tabular}

Trichlorethylene can be used in the estimation of fat in dried milks and patent foods containing dried milk and malt extract. The following method was devised, and, if the details are carefully followed, excellent results may be obtained.

Half a gram of the milk is quickly weighed out and spread over the bottom of a flat dish, and heated in the water-oven until the weight is constant. 
A small quantity of the dried milk and sand $*$ are ground together in a small mortar (which has been previously washed out with trichlorethylene and dried) till thoroughly mixed, a further quantity of milk and sand are added and again ground as before, and so on until all the milk is mixed with the sand. This is transferred to a fat-free dried paper thimble, and it should occupy as nearly as possible one-third of the volume of the thimble. A fat-free piece of filter-paper is placed in the top of the thimble to prevent the sand being splashed out. The extraction is carried out in a Soxhlet apparatus for fully three hours, the flask being heated over gauze, with a small flame. The flask is dried to constant weight, air being gently blown in about every ten or fifteen minutes to expel heavy vapours. The fat is dissolved in petroleum ether, any insoluble matter is allowed to settle and the ether decanted off. The flask and its contents are dried and weighed; the difference between the first and last weight is the weight of fat. Only purified trichlorethylene should be used, and accuracy in the estimations depends on keeping out every trace of moisture.

Below are the results of some estimations by this method, compared with those obtained by other ether extraction methods.

\begin{tabular}{|c|c|c|c|c|c|c|}
\hline \multirow{2}{*}{ Description of Milk. } & & \multirow{2}{*}{$\begin{array}{l}\text { Trichlorethylene } \\
\text { Method. } \\
\text { Fat Per Cent. }\end{array}$} & \multicolumn{3}{|c|}{ Fat by Extraction with Ether. } & \multirow{2}{*}{$\begin{array}{l}\text { Difference } \\
\text { Per Cent. }\end{array}$} \\
\hline & & & $\begin{array}{l}\text { Fat Per } \\
\text { Cent. }\end{array}$ & Analyst. & Method. & \\
\hline Full cream & $\ldots$ & $28 \cdot 25$ & $28 \cdot 24$ & Richmond & Gottlieb & +0.01 \\
\hline Patent cream & $\ldots$ & $27 \cdot 00$ & $26 \cdot 75$ &, & , & +0.25 \\
\hline Separated cream ... & $\ldots$ & 0.86 & 0.83 & 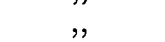 &, & $+0 \cdot 03$ \\
\hline Half cream $\quad \ldots$ & .. & $15 \cdot 20$ & $14 \cdot 89$ & 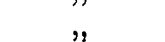 & 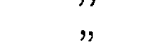 & +0.31 \\
\hline Ordinary cream $\ldots$ & $\ldots$ & $24 \cdot 36$ & $24 \cdot 36$ & & & \pm 0.00 \\
\hline Full cream $\quad \ldots$ & $\ldots$ & $29 \cdot 37$ & $29 \cdot 58$ & Chapman & Adams & -0.21 \\
\hline Separated cream ... & $\ldots$ & $1 \cdot 18$ & $1 \cdot 27$ & Bilson & Gottlieb & -0.09 \\
\hline Milk and malt extract & $\ldots$ & $11 \cdot 90$ & $11 \cdot 93$ & , & $\left(\begin{array}{l}\text { Werner- } \\
\text { (Schmidt) }\end{array}\right.$ & -0.03 \\
\hline
\end{tabular}

The necessity of keeping to the details of the above method is shown by the following determinations made on three of the above milks.

\begin{tabular}{c|c|c|c}
\hline $\begin{array}{c}\text { Fat Per Cent., extracted } \\
\text { from Moist Sample } \\
\text { (iround. No Sand. }\end{array}$ & $\begin{array}{c}\text { Fat Per Cent., extracted, } \\
\text { Dly, mixed with Sand, } \\
\text { without Grinding. }\end{array}$ & $\begin{array}{c}\text { Fat Per Cent., } \\
\text { obtained by } \\
\text { Above Method. }\end{array}$ & $\begin{array}{c}\text { Fat Per Cent., } \\
\text { extracted with } \\
\text { Ether. }\end{array}$ \\
\hline 27.87 & $24.12 \dagger$ & 29.37 & 29.58 \\
0.53 & 0.95 & $\begin{array}{r}1.18 \\
11.90\end{array}$ & 11.93 \\
0.85 & 11.28 & 1.27 & \\
\hline
\end{tabular}

* The sand used is purified by first well washing with water, drying thoroughly, and washing with richlorethylene. It is then well dried, ignited, and bottled while still hot.

$\dagger$ This sample became very lumpy on drying; hence the low fat figure. 
However carefully this method is carried out, the resulting fat is always a pale straw colour. What this is due to has not been found out. Perhaps the fact that the fat is heated to more than $50^{\circ} \mathrm{C}$. higher than when extracted with ether may have something to do with it, or, more probably, some colouring matter is extracted.

Chemical Properties. - Trichlorethylene possesses interesting chemical properties, and it may possibly be found useful in organic syntheses. As this would form a subject in itself for an investigation, its behaviour towards some common reagents was all that was here attempted.

A comparison of some characteristic reactions of this compound with chloroform and carbon tetrachloride is given in the following table:

\begin{tabular}{|c|c|c|}
\hline Trichlorethylene. & Chloroform. & Carbon Tetrachloride. \\
\hline $\begin{array}{l}\text { Does not give isocyanide re- } \\
\text { action. }\end{array}$ & Gives isocyanide reaction. & Gives isocyanide reaction. \\
\hline $\begin{array}{l}\text { Joes not reduce Fehling solu- } \\
\text { tion. }\end{array}$ & Reduces Fehling solution. & Reduces Fehling solution. \\
\hline $\begin{array}{l}\text { Decomposed into carbon, } \\
\text { chlorine, HCl, etc., on } \\
\text { passing through red-hot } \\
\text { tube. }\end{array}$ & $\begin{array}{l}\text { Decornposed into chlorine } \\
\text { and } \mathrm{HCl} \text { on passing } \\
\text { through red-hot tube. }\end{array}$ & - \\
\hline $\begin{array}{l}\text { Decomposes slightly in sun- } \\
\text { light. }\end{array}$ & Decomposes in sunlight. & $\begin{array}{l}\text { Does not decompose in } \\
\text { sunlight. }\end{array}$ \\
\hline $\begin{array}{l}\text { Practically unattacked by } \\
\text { KOH. }\end{array}$ & Decomposed by KOH. & Decomposed by KOH. \\
\hline
\end{tabular}

Trichlorethylene absorbs large quantities of bromine in sunlight, forming a heavy, colourless liquid, which, when distilled, immediately decomposes with the liberation of bromine. It is only slowly attacked by boiling sulphuric and hydrochloric acid, but hot nitric acid attacks it violently. If the vapour of trichlorethylene is passed through a tube heated to redness, carbon, chlorine, and hydrochloric acid are given off, while a black, acid, fuming liquid condenses. In the cool part of the tube small, clear, needle-shaped crystals are found.

Toxic Properties.-The vapour of trichlorethylene, when inhaled in small quantities diluted with air, gives headache to some people, while others are unaffected. When inhaled in larger quantities, it produces symptoms similar to those produced by anæsthetics. It has a burning taste, irritates the throat and causes coughing.

\section{Summaky.}

1. Trichlorethylene is a colourless, easily volatile, extracting agent.

2. It dissolves practically all organic compounds that do not contain two or more carboxyl or hydroxyl groups, also some inorganic substances. 
3. It may be successfully employed for the determination of fats, especially in dried milks, if certain precautions be observed.

4. As a general solvent it appears to offer few advantages over those commonly in use, except that it is non-inflammable. As it is an unsaturated compound, it cannot be employed with oxidising agents; its solvent properties resemble those of chloroform and carbon tetrachloride, but it withstands the action of alkalis much better.

In conclusion, I desire to thank Mr. A. Bilson, who has undertaken a great deal of the routine work in connection with the latter part of the paper.

Messrs. Greef and Co., 20, Eastcheap, E.C., kindly supplied a quantity of "Westrosol" for the experiments.

\section{Discussion.}

Dr. Dyer said that with many substances the drying made no difference, but in the case of linseed cake or maize meal the drying in air caused oxidation of the oil, so that a portion of it could not be extracted. If a solvent was used which made preliminary drying necessary, the substance should be dried in a current of coal-gas.

Mr. E. R. BotTon remarked that he should expect trichlorethylene to give off bydrochloric acid, as was the case with carbon tetrachloride. This impression seemed to be confirmed by the fact that, in the case of a sample which he had allowed to stand for some time in a corked glass bottle, the cork became disintegrated and strongly acid. In considering the suitability of an extracting agent for commercial use, its specific heat must be taken into account, because the amount of heat required would be a factor as well as the boiling-point.

Mr. Chaphan said that he had obtained a quantity of this substance, and had been able to separate a considerable fraction which was fairly pure. With the impure substance hydrochloric acid was given off, and also some other compounds, but scarcely any when the substance was properly purified. It readily acted on cork, but this was no proof that any decomposition had taken place.

Mr. Richmond remarked that, in speaking of the action of the substance on cork, Mr. Scopes meant that it dissolved out certain portions of the cork in the same way as chloroform and other substances. It did not seem to be much worse in this respect than ordinary solvents.

Mr. L. M. NASH suggested that the proportion of water which the substance would dissolve might be readily determined by the calcium carbide method.

Mr. G. N. Huntuy said that he had tried to use trichlorethylene for making a constant vapour-jacket, but had found it quite useless for that purpose owing to its very wide range of boiling-point. About a year ago a sample had been submitted to him with certain definite questions as to its action on metals and the action of light upon it. It always contained a little water, being apparently somewhat hygroscopic. A sample containing a mere trace of water became acid when exposed to light, and if heated with iron to $100^{\circ} \mathrm{C}$. it readily acted on the metal. A point which had not been mentioned was its extremely low latent heat of vaporisation-one of the lowest known-and this increased the difficulty of purifying it. In the case of 
several samples which were supposed to boil at $88^{\circ} \mathrm{C}$., his attempts at purification by fractionation in a Young column had failed. The liquid started boiling at about $80^{\circ} \mathrm{C}$., 50 per cent. coming over at about $87^{\circ} \mathrm{C}$., and at least 5 per cent. was left behind at $90^{\circ} \mathrm{C}$., and 1 per cent. at $100^{\circ} \mathrm{C}$., which would rather interfere with its use for determining fat. Its latent heat of vaporisation was roughly about one-tenth of that of water. This meant, of course, that a condenser need scarcely be used at all, sufficient condensation being obtained in a plain glass tube. It had a corrosive action on cork, probably owing to the formation of hydrochloric acid.

Mr. Chapuan said that the sample with which he had worked must have been very different from that submitted to Mr. Huntly. He had obtained from it a considerable proportion distilling almost constantly at $88^{\circ}$ to $89^{\circ} \mathrm{C}$., and had found no difficulty in working with it in an ordinary still-head.

Dr. G. KoLLER said that "Westrosol" had been made in England during the last twelve months only. When trichlorethylene was first put on the market it was not so pure as at the present time, and had a rather wide range of boiling-points. It was also, at that time, difficult to separate the impurities from it and to obtain a fraction of uniform boiling-point. At present, however, no trichlorethylene is put on the market, even for technical purposes, which would have a wider range of boilingpoints than $3^{\circ}$ or $4^{\circ} \mathrm{C}$, and for special purposes the product is not considered satisfactory unless 99.5 per cent. of it distilled over between $88^{\circ}$ and $90^{\circ} \mathrm{C}$. There is no difficulty now in preparing for sale pure trichlorethylene which would distil completely within $1 \frac{1}{2}^{\circ}$ or $2^{\circ} \mathrm{C}$.; but for technical purposes-it was used on a very large scale for extracting oils and fats from seeds, and all kinds of fatty and greasy materials-it was quite suffient if the boiling-point did not vary beyond a margin of $2^{\circ}$ or $3^{\circ} \mathrm{C}$. When exposed to direct sunlight for any length of time the substance gave off slight traces of hydrochloric acid. This drawback it shared with chloroform and other chloro-derivatives, also with carbon bisulphide, etc. When stored in iron vessels, it had no action on the iron, nor would there be under working conditions any decomposition resulting in the formation of hydrochloric acid. If the substance were not pure, however, decomposition could take place, and would be more marked than with the pure substance under the inflience of direct light.

All the chlorethanes, in the presence of water, acted on iron, although not to the same extent as carbon tetrachloride. They therefore could not be used in iron plant for commercial or technical purposes.

The ethylene compounds are very stable in that respect, and are commonly used in ordinary iron extractors with the most satisfactory results. He was afraid that the manufacturer's attention had not been called sufficiently to the fact that, although quite stable under working conditions, the samples showed at times signs of susceptibility to light after lengthy exposure.

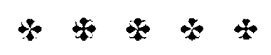

